\title{
Riscos, saúde e justiça ambiental: o protagonismo das populações atingidas na produção de conhecimento
}

\author{
Environmental risk, health and justice: the protagonism \\ of affected populations in the production of knowledge
}

Marcelo Firpo Porto ${ }^{1}$

Renan Finamore ${ }^{1}$
${ }^{1}$ Centro de Estudos da Saúde do trabalhador e Ecologia Humana, Escola Nacional de Saúde Pública Sergio Arouca, Fundação Oswaldo Cruz. Av. Leopoldo Bulhões 1480, Manguinhos. 21041210 Rio de Janeiro RJ. marcelo.firpo@ensp.fiocruz.br
Abstract This article discusses the role of populations affected by environmental injustice situations in the production of knowledge about environmental health stemming from inequalities and discrimination in the distribution of risks and benefits of economic development. Special attention is given to the epistemological and political limits to producing knowledge and alternatives that enable advances in building more just and sustainable societies are highlighted. Based on a broader view of health, the limits of scientific approaches are called into question by acknowledging the importance of local knowledge are discussed, either to analyze environmental risks or their effects on health, including epidemiological studies. These limits are linked primarily to the concealment of conflicts and uncertainties, the lack of contextualization of exposure to risk and effects on health, as well as the difficulties of dialogue with the communities. The article also presents contributions and advances presented by environmental justice movements. The conclusion is that a constructivist, procedural and democratic perspective of confronting forms of knowledge and practices can guide the scientific production to benefit of environmental justice.

Key words Environmental justice, Environmental health, Popular epidemiology, Local knowledge
Resumo É discutida a participação das comunidades em situações de injustiça ambiental na produção de conhecimentos, as quais são decorrentes de desigualdades e de discriminações na distribuição de riscos e benefícios do desenvolvimento econômico. São destacados os limites epistemológicos e políticos para a produção de conhecimentos e de alternativas que possibilitem o avanço na construção de sociedades mais justas e sustentáveis. A partir de uma visão ampliada de saúde são discutidos os limites das abordagens científicas em reconhecer a importância do saber local, seja para analisar riscos ambientais ou seus efeitos à saúde, incluindo os estudos epidemiológicos. Tais limites relacionam-se basicamente ao ocultamento de conflitos e incertezas, à falta de contextualização da exposição aos riscos e efeitos sobre a saúde, assim como às dificuldades de diálogo com as comunidades. O artigo apresenta ainda contribuições e avanços decorrentes de movimentos por justiça ambiental. Concluiu-se que uma perspectiva construtivista, processual e democrática de confrontação de saberes e práticas poderá orientar a produção científica em prol da justiça ambiental.

Palavras-chave Justiça ambiental, Saúde ambiental, Epidemiologia popular, Saber local 


\section{Introdução}

\section{A saúde, ambiente e conflitos na perspectiva da justiça ambiental}

Este artigo discute o papel e o protagonismo na produção de conhecimento por parte das populações afetadas por riscos e problemas de saúde em situações de conflito e injustiça ambientall $^{1}$. Tais conflitos são centrais no que autores da corrente ecossocialista ${ }^{2}$ denominam de segunda grande contradição do capitalismo contemporâneo em tempos de globalização, e que vem a se somar ao histórico conflito capital-trabalho. Ela está relacionada às condições de produção e inclui questões ambientais, identitárias, de direitos humanos, étnicas e de gênero. Seus principais protagonistas são coletivos contra hegemônicos organizados em torno de agendas de mudança social tanto próprias e locais como ampliadas, como a luta antiglobalização e contra o neoliberalismo. Tais coletivos podem ser formados por ambientalistas, frentes de combate ao racismo, feministas, povos tradicionais, agricultores familiares ligados à reforma agrária e à agroecologia, além de inúmeros grupos sociais que vivem nas periferias urbanas e nas chamadas "zonas de sacrifício”, nas quais populações excluídas e discriminadas são forçadas a viver e a trabalhar em condições indignas ${ }^{3}$. Eles fazem parte de novos movimentos sociais ${ }^{4}$ que demandam e impulsionam políticas emancipatórias no atual momento histórico, e se mobilizam no enfrentamento de conflitos ambientais através de organizações de justiça ambiental (OJA). Tais organizações são nucleadas pelas comunidades atingidas nos territórios que vivem e trabalham, articuladas em redes constituídas por movimentos sociais, ONGs, sindicatos e mesmo instituições públicas parceiras, como grupos de pesquisa e o Ministério Público, que atuam na defesa de suas bandeiras sempre que suas missões, compromissos e níveis de autonomia os permitem.

Nesses contextos, problemas de saúde e ambiente são compreendidos no interior de conflitos ambientais que expressam disputas entre, de um lado, interesses das comunidades, organizações e movimentos sociais aliados e, de outro, agentes sociais beneficiados por atividades econômicas e produtivas as mais diversas tais como: mineração, exploração e refino de petróleo, produção de ferro e aço, construção de hidrelétricas, aterros oficiais ou clandestinos de resíduos, o agronegócio e o uso intensivo de agroquímicos, a indústria da especulação imobiliária e dos gran- des eventos nos espaços urbanos, como a Copa do Mundo e as Olimpíadas. Tais conflitos resultam, no atual capitalismo globalizado, de um comércio internacional injusto e insustentável assentado numa divisão internacional do trabalho e dos riscos que coloca sobre o ombro dos países, territórios e das populações mais vulneráveis as cargas mais pesadas do desenvolvimento econômico. Como consequência da fragilização do poder dos Estados Nacionais e sua subordinação ao ideário neoliberal, a capacidade dos governos e instituições de regularem o próprio mercado e implementarem políticas públicas distributivas e de defesa dos bens públicos é reduzida, esgarçando a tensão das sociedades modernas entre regulação e emancipação, permitindo ainda retrocessos de práticas de apropriação e violência que marcaram as eras colonial e imperialista do capitalismo e ainda sobrevivem ${ }^{5}$.

Nosso argumento principal - a importância das comunidades e movimentos por justiça ambiental na produção de conhecimento - atualiza, no campo da saúde ambiental, uma tradição importante seguida pela medicina social latinoamericana e pela saúde coletiva de ampliar e politizar o conceito de saúde enquanto expressão de direito e cidadania, tal como explicitado na VIII Conferência Nacional de Saúde e materializado na Constituição Federal de 1988 e na Lei Orgânica de Saúde de $1990^{6}$. Esta discussão também se encontra presente na Organização Mundial de Saúde (OMS) nos chamados determinantes sociais da saúde, ao chamar a atenção para as desigualdades, inequidades e discriminações sociais como importantes "causa das causas" dos problemas de saúde de inúmeros países ${ }^{7}$. Tais visões confluem para a compreensão da Ecologia Política e da Justiça Ambiental de que a saúde deve ser entendida a partir de um contexto social e histórico mais amplo de desigualdades e assimetrias sociais, políticas e econômicas presentes entre continentes, países ou dentro destes. Apesar disso, Freitas ${ }^{8}$ indica a baixa incidência de abordagens participativas na produção científica da saúde coletiva brasileira.

Esta breve introdução é relevante para melhor precisarmos o significado de nosso objeto: ao discutirmos a participação das comunidades em situações de injustiça ambiental na produção de conhecimentos não nos referimos apenas ao aperfeiçoamento das áreas e métodos científicos - sejam quantitativos ou qualitativos - que vêm sendo desenvolvidos e utilizados no campo da saúde ambiental. O que se encontra em jogo, como veremos, são os limites epistemológicos e 
políticos para a produção de conhecimentos, bem como o desenvolvimento de alternativas que possibilitem avançarmos na construção de sociedades mais justas e sustentáveis.

Para dar sequência a esta argumentação, o artigo encontra-se estruturado da seguinte forma: inicialmente discutimos dois limites importantes na produção de conhecimentos e prática institucional no campo da saúde ambiental: o primeiro está relacionado ao próprio conceito de risco ambiental e a forma como é analisado e gerenciado. O segundo se refere ao estudo dos efeitos à saúde dos problemas e riscos ambientais, tendo aqui a abordagem quantitativa da epidemiologia dos fatores de risco um papel central. $\mathrm{Na}$ segunda parte do artigo, apontamos como os diversos conhecimentos locais mobilizados e sistematizados pelas populações atingidas e organizações de justiça podem avançar não apenas na capacidade de gerar respostas cientificamente mais adequadas, mas também, e fundamentalmente, em sua articulação com a mobilização política dos sujeitos coletivos na transformação da própria sociedade e seus processos geradores de injustiças ambientais. Na conclusão, apontamos alguns dos desafios de uma ciência cidadã ou militante em prol da justiça ambiental.

\section{O conceito de risco ambiental: limites e potenciais para a justiça ambiental}

Segundo a Agência de Proteção Ambiental dos Estados Unidos (EPA $)^{9}$, a análise de riscos é uma ferramenta central para a regulação e controle dos riscos ambientais, sendo realizada em três estágios: avaliação, caracterização e gestão. A avaliação sistematiza informações científicas sobre as propriedades perigosas dos agentes ambientais, a relação dose-resposta e a extensão da exposição humana a esses agentes. A caracterização dos riscos define condições e probabilidades nas quais populações ou indivíduos expostos serão prejudicados e em que grau. Finalmente a gestão dos riscos busca integrar aspectos políticos, sociais, econômicos e de engenharia a fim de analisar, comparar e selecionar as respostas apropriadas de gestão para um perigo potencial crônico para a saúde. A implantação dessas respostas, do ponto de vista tecnológico e organizacional, é operacionalizada por práticas de gerenciamento em situações reais, como uma fábrica em funcionamento.

Diversos autores apontam sérios limites desse modelo científico de abordar o risco ${ }^{10,11}$, já que não confere àqueles em situação de risco o direito de decidir como lidar com ele, inclusive recu- sando-o, fato corriqueiro no cotidiano de pessoas quando usufruem da liberdade. De fato, no caso de inúmeros riscos ambientais as populações expostas aos riscos não têm voz nas estratégias usadas para gerenciá-los, papel que compete basicamente às empresas - os criadores dos riscos -, aos especialistas e instituições reguladoreas. Tal fato é agravado por duas dimensões relevantes: a epistemológica e a política. A primeira tem a ver com a questão do conhecimento e das incertezas, ou seja, o que se sabe ou não sobre os riscos, seus efeitos e a capacidade de controlá-los. Este problema é agravado pelo nível das incertezas em jogo: será maior na medida em que os riscos tornam-se mais complexos e incertos, chegando à ignorância ou incerteza epistemológica ${ }^{12}$, caracterizada pela inexistência de corpos teóricos maduros para analisar situações e prever cenários futuros envolvendo riscos.

A dimensão política tem a ver com um aspecto central não só dos movimentos por justiça ambiental, mas da própria saúde pública, cuja criação e institucionalização respondem a demandas de se proteger a população, em especial a mais desprotegida, contra os males decorrentes de interesses privados e da concentração de poder político e econômico. Transportada tal discussão para a análise e gestão dos riscos, o que fazer se perigos atingem justamente os mais desprovidos de poder, as populações mais vulneráveis, pobres e discriminadas, as quais encontram-se em grande desvantagem desde o início do processo de análise dos riscos ambientais? Este problema é agravado em situações que envolvem riscos mais complexos e com maiores incertezas, mas também aqueles que, apesar de conhecidos e potencialmente controláveis, podem produzir inúmeros perigos diante de vulnerabilidades das populações e instituições fiscalizadoras; em países cujas organizações do trabalho sejam autoritárias; ou ainda de restrições econômicas em empresas e setores que acabam por não implementar protocolos básicos de manutenção e segurança ${ }^{1}$. Em contextos vulneráveis como esses, ocorre uma desvalorização da vida dos trabalhadores e populações atingidas em diferentes momentos da análise e gerenciamento de riscos, que se tornam artificiais ${ }^{13}$, favorecendo externalidades negativas ${ }^{14}$ e o que ergonomistas denominam modos degradados de produção ${ }^{1}$. Isso pode se expressar de diferentes formas, como na subestimação dos riscos e da vida humana nos cálculos de investimentos; nos processos acelerados de licenciamento ambiental, com mecanismos restritivos de participação da 
sociedade e, em especial, das populações atingidas; na prática ineficiente ou empresarialmente cooptada das instituições fiscalizadoras; ou ainda em estudos e pesquisas sobre riscos ambientais, sejam eles sobre momentos passados, presentes ou cenários futuros que desconsideram visões precaucionárias ${ }^{12}$ em prol das expectativas positivas do crescimento econômico.

\section{Os limites no campo da saúde pública: os estudos epidemiológicos dos fatores de risco}

A exposição aos riscos ambientais e seus efeitos à saúde humana, como no caso da contaminação química atmosférica ou de corpos hídricos, é um elemento importante para a análise de problemas de saúde ambiental. Dentro do campo específico da saúde pública, uma discussão importante diz respeito ao chamado nexo causal ou epidemiológico. No campo jurídico, o conceito de nexo causal é aplicado de forma genérica enquanto vínculo que existe entre o comportamento ou conduta de certo agente e o resultado por ele produzido, o que permite estabelecer relações de causalidade a partir da ligação entre o comportamento e o efeito gerado. Com isso tenta-se verificar se certa ação (ou omissão) produziu ou influenciou no resultado em questão. De forma análoga, no campo da saúde ambiental e do trabalhador ${ }^{15}$ o nexo causal busca estabelecer associações com base em dados empíricos entre certa doença e a exposição a certos riscos, sejam eles presentes no ambiente de trabalho ou nos ambientes gerais onde as pessoas vivem e circulam. O estabelecimento desse nexo, contudo, pode ser tarefa bem complexa, já que muitos problemas de saúde potencialmente relacionados aos riscos ambientais e/ou ocupacionais possuem inúmeras etiologias, e são raras as doenças cuja causa é exclusivamente atribuída a algum risco ambiental específico, sendo por isso difícil demonstrar essa associação de forma direta e incontroversa. Uma exceção é o caso do mesotelioma maligno, um tipo de tumor que ocorre na pleura e envolve o pulmão, pois o único agente cientificamente reconhecido que o provoca é o asbesto, fibra mineral proibida na Europa e em vários países, mas ainda permitida no Brasil ${ }^{16}$.

Dentro das ciências biomédicas, existem duas formas principais para se estabelecer a associação entre exposição aos riscos ambientais ou fatores de risco. Do ponto de vista individual, pessoas e situações específicas são avaliadas pela medicina clínica, na qual especialistas ou peritos podem estabelecer o nexo causal a partir da existência de um forte conjunto de evidências associadas às características do histórico da exposição ocupacional/ambiental e dos sintomas clínicos, com o apoio de outros profissionais. Outra alternativa, de maior relevância para este artigo, são os estudos epidemiológicos em que as associações são realizadas para conjuntos de populações expostas a partir de diversas bases de dados, em particular de morbidade ou mortalidade.

Embora existam diferentes tipos de estudos e abordagens, a epidemiologia amplamente usada pela saúde ambiental tende a se concentrar nos fatores de riscos presentes em populações expostas. São então calculadas, comparadas e analisadas taxas de incidências de doenças e mortes com populações expostas e não expostas - chamados grupo controle - a certos fatores, sejam eles ambientais, sociais, econômicos ou comportamentais. Tais estudos podem se realizar num dado momento (caso dos estudos ecológicos e de caso-controle), ou levar em conta um período mais longo de tempo (estudos tipo coorte), buscando medir os efeitos de certas variáveis ou fatores de risco sobre a população estudada, sendo por isso bem mais caro e difícil de ser realizado. Contudo, muitas vezes tais estudos são difíceis de realizar ou chegam a resultados inconclusivos, e há várias razões para isso.

Por exemplo, a existência de séries históricas com dados dos riscos ambientais, características da exposição e da saúde das populações em comunidades específicas são mais difíceis de obter. Também o contexto de cada situação tende a ser bem distinto um do outro, pois podem existir simultaneamente diferentes riscos e contextos de exposição, sendo bastante complexo estabelecer associações estatísticas. Além disso, problemas de saúde comuns, especialmente em contextos e populações vulneráveis, podem se tornar mais difíceis de terem percebidos sua associação com os riscos ambientais, ainda que estes possam agravar problemas justamente nas pessoas mais suscetíveis. Sãos exemplos vários problemas respiratórios, dermatológicos ou oftalmológicos cuja frequência pode aumentar, de forma mais sutil ou intensa, em decorrência da poluição atmosférica proveniente de fábricas, veículos, atividade de mineração ou queimadas em região de agricultura. A pesquisa ex-post facto torna a epidemiologia bastante conservadora, pois ainda que associações positivas sejam encontradas, os resultados podem ser revelados após a ocorrência de inúmeras doenças e mortes que não teriam acontecido caso a exposição aos riscos não fosse permitida numa perspectiva precaucionária. 
Podem existir fortes tensões no diálogo entre instituições e profissionais de saúde com as populações atingidas e as OJA em torno dos estudos epidemiológicos. Mesmo que sejam realizados, com todas as dificuldades de custos, independência dos profissionais e tempo de realização, os problemas podem advir de resultados inconclusivos ou, ainda que estabeleçam certas associações, podem ser excessivamente abstratos e de difícil compreensão. Por exemplo, imaginemos que certo estudo indique que pessoas que moram próximas (até dois quilômetros) de certo tipo de fábrica tenham duplicado o risco de desenvolver certa doença, como um tipo particular de câncer. Se a incidência "normal" ou esperada de câncer na população em geral é de dois casos a cada 100 mil por ano, isso significa que a incidência em moradores próximos de fábricas poderá ser de um caso a cada 25 mil. Tal informação pode ser bastante complicada de entender ou assimilar, e por vários motivos. O estudo epidemiológico que chegou a este resultado, para ter força de associação estatística, pode ter levantado dados de muitos milhares de pessoas em distintas fábricas sem considerar as diferentes intensidades de poluição geradas por cada uma delas. Portanto, o resultado final considera uma média global que pode não levar em consideração as possíveis diferenças, eventualmente de grande importância, no tipo de tecnologia, gestão ambiental, condições climáticas, características alimentares, qualidade da habitação e outros elementos.

Além disso, para uma comunidade de algumas centenas de pessoas, por exemplo, 250 vivendo próximas a uma fábrica, estranho o discurso de especialistas que afirmam ser muito pouco provável a ocorrência deste problema específico de câncer, pois mesmo com uma taxa de risco duplicada, seria esperado em média um caso de câncer a cada 100 anos! Para muitas pessoas esta afirmação pode ser considerada uma afronta quando, além de inúmeros outros problemas de saúde cujo aparente agravamento é percebido como associado à poluição industrial, surge alguém com aquele caso específico de câncer justamente naquela pequena comunidade. Isso revela os limites dos estudos epidemiológicos, pois, ainda que bem feitos, revelam associações estatísticas válidas para coletivos ou populações maiores, e não ajudam muito para nexos individuais e grupos expostos em menor número e contextos específicos de exposição.

O principal propositor da chamada epidemiologia popular, Phil Brown, já apontava ${ }^{17,18}$ em 1987, que os epidemiologistas preferiam fal- sos negativos a falsos positivos, ou seja, preferem reivindicar nenhuma associação entre variáveis quando existe uma do que reivindicar uma eventual falsa associação. Seguindo a mesma linha, epidemiologistas como Neil Pearce ${ }^{19-21}$ e Nancy Krieger ${ }^{22}$ discutem em artigos posteriores como este problema continuou a afetar os estudos epidemiológicos na virada do século, e por diversas razões, como o crescente foco no indivíduo em vez da população, a desconsideração com os contextos de exposição, o reducionismo biomédico e mesmo a influência de setores industriais empresariais, os quais contratam especialistas com o intuito de atacar estudos e caracterizálos como "junk science" - entendida como ciência desqualificada - quando estes confrontam interesses econômicos corporativos. Tais limites buscam ser superados por abordagens como a dos determinantes sociais, teorias de cunho ecossocial que abarcam diferentes perspectivas e dinâmicas multinível, ou ainda os estudos baseados na comunidade (community based), que discutiremos a seguir.

\section{Saúde e justiça ambiental: \\ o papel das populações atingidas enquanto protagonistas na produção de conhecimento}

Diante dos limites apresentados nos tópicos anteriores, que podem ser ampliados por autores da epidemiologia social e crítica, inclusive a relevante contribuição no cenário latino-americano de Jaime Breilh ${ }^{23}$, em sua proposta de monitoramento participativo, torna-se relevante indicar potencialidades na produção de conhecimentos que vêm sendo realizadas pelos movimentos por justiça ambiental a partir de ações e mobilizações protagonizadas por populações atingidas e organizações parceiras.

Em comum a todas as iniciativas de mobilização coletiva encontra-se o sentimento de injustiça frente ao descaso e imobilização de muitas instituições, empresas, cientistas e profissionais frente às suspeitas ou denúncias realizadas. $\mathrm{Ou}$ tro aspecto importante é a busca de tais populações assumirem-se como sujeitos - e não simples objetos - da própria realidade que vivenciam, o que inclui a disputa por valores, por critérios de priorização e pela validação de argumentos que buscam explicar e contextualizar os problemas e controvérsias em questão ${ }^{24,25}$.

$\mathrm{Na}$ perspectiva da justiça ambiental, as dimensões epistemológicas e políticas encontramse fortemente imbricadas, pois conhecer signifi- 
ca simultaneamente poder: o de compreender processos e fenômenos complicados e inacessíveis por envolverem especialidades técnico-científicas que mesclam áreas distintas como engenharia, medicina, economia, direito, ecologia, ciências sociais, psicologia e jornalismo; o de tornar visível conflitos, problemas, denúncias e demandas sistematicamente negligenciadas pela mídia e as instituições; o de contextualizar e demonstrar de forma mais articulada o sofrimento e as preocupações vividas pelas comunidades; o de disputar argumentos diante de processos e decisões no âmbito das instituições e políticas públicas; o de prevenir ou reverter situações de risco existentes ou futuras; o de garantir assistência médica adequada aos que necessitam; o de forçar o cumprimento da legislação ou, quando inexistente, de batalhar pela criação de leis mais protetoras e cidadãs; e talvez o mais importante, o de gerar estratégias que transformem as populações afetadas em sua condição humana em sujeitos de enfrentamento e transformação da sociedade. É justamente este processo de transformação da condição de grupos vulneráveis com vozes ocultas para sujeitos coletivos que, através de sua organização comunitária e política articulados em redes e movimentos mais globais, buscam transformar sua realidade local em solidariedade com as lutas de outras populações e territórios, tal como na estratégia do projeto internacional denominado EJOLT ${ }^{14}$.

Nesse contexto, os riscos ambientais são percebidos de forma mais ampla em sua relação com a perda de direitos, discriminações, racismo e outras formas de violência impostas por agentes econômicos poderosos, ou ainda pela omissão ou mancomunação de instituições públicas que deveriam estar a serviço da proteção ambiental, da saúde pública e dos direitos humanos. A percepção dos perigos iminentes ou existentes podem se originar de duas dinâmicas básicas: a partir das vivências e experiências cotidianas acumuladas pelas populações, movimentos sociais e Organizações de Justiça Ambiental (OJA) nos territórios, locais de trabalho ou moradia em torno dos riscos e/ou possíveis efeitos à saúde; e da organização em coletivos que se articulam com redes e movimentos sociais na crítica ao modelo de desenvolvimento, à globalização neoliberal, ao comércio injusto e através bandeiras e agendas específicas, sejam elas identitárias, ambientalistas, sindicais, feministas, de combate ao racismo, pela reforma agrária, agroecologia ou economia solidária. Dentro dos territórios em uso ou em disputa ${ }^{26}$, as comunidades convivem com situações de risco percebidas, portanto, como de injustiça ambiental, sejam elas provocadas por indústrias, tecnologias, depósitos de resíduos ou outras atividades econômicas potencialmente perigosas à saúde e/ou ao meio ambiente.

A dimensão do conhecimento pode ser trabalhada de inúmeras formas, tendo as populações e OJA um papel central. Por exemplo, riscos ambientais e problemas de saúde podem ser sistematizados a partir da compilação e leitura crítica de trabalhos acadêmicos e profissionais, sejam eles livros, artigos, relatórios, relatos jornalísticos, filmes ou materiais produzidos no âmbito da justiça. Também pode haver a produção direta de materiais em diversas linguagens por parte das próprias populações atingidas e organizações de justiça ambiental, que sistematizam problemas ambientais e de saúde ocorridos no passado e presente ${ }^{24}$. Tais narrativas produzem, muitas vezes em linguagens populares e inovadoras, inventários, mapeamentos e relatos importantes de casos de poluição, doenças e mortes, acidentes, desastres e catástrofes relacionados com várias atividades econômicas, produtivas e tecnológicas. Também sistematizam em linhas do tempo as várias formas de atuação das instituições e do poder público, incluindo a crítica às análises de risco e às estratégias criadas pelas populações e OJA para lidar, enfrentar e superar os problemas.

A forma como populações, especialistas e pesquisadores podem se articular são inúmeras. Uma condição central, sob a ótica da justiça ambiental, está relacionada a como profissionais e cientistas respeitam solidariamente as comunidades atingidas em suas demandas, autonomia e protagonismo diante dos conflitos em questão. Trata-se, portanto, de um delicado processo de formação de laços de confiança constituintes das comunidades ampliadas de práticas, epistêmicas ou de pesquisa-ação que, durante certo período, produzem de forma compartilhada conhecimentos ${ }^{27}$.

O compartilhar de tais trabalhos e experiências entre diferentes organizações de justiça ambiental no âmbito nacional ou internacional em torno de problemas específicos permite formas de intercâmbio e aprendizado com inteligência coletiva e solidária, sendo uma estratégia importante para que comunidades possam prevenir ou impedir certos problemas antes que os mesmo ocorram. Por exemplo, participando das decisões, exigindo informações adequadas, barrando certas atividades econômicas/produtivas perigosas, exigindo as "Best Available Technologies" (BAT), intervindo nas estratégias de gestão am- 
biental e gerenciamento de riscos, ou mesmo participando da formulação projetos de investigação de riscos ou requerendo novos estudos e serviços de saúde, entre outras ações possíveis.

Tais práticas de produção de conhecimento assumem as premissas básicas de uma ciência cidadã ${ }^{28}$ ou militante ${ }^{14}$, ou ainda uma ciência para a justiça ambiental ${ }^{25}$ ou "Street Science" na expressão adotada por Jason Corburn ${ }^{29,30}$, baseadas na importância do conhecimento local das populações que vivenciam em seu cotidiano situações de risco e injustiças. $\mathrm{O}$ conhecimento local tem como contraponto a noção de conhecimento profissional (especializado, acadêmico, industrial), que tende a descontextualizar e a "congelar" a compreensão de como as populações vivem os problemas ambientais e de saúde em seu cotidiano. A possível integração entre conhecimento local e outras formas de conhecimento potencializam o desenvolvimento de práticas mais democráticas e de justiça distributiva por reduzirem assimetrias de poder e acesso a recursos que conformam contextos de vulnerabilidade socioambiental. Para Corburn ${ }^{29}$, o conhecimento local incorpora inúmeros elementos importantes, como as noções de identidade (social) e lugar; evidências oriundas de tradições, intuição, imagem, história oral e narrativas que trazem a tona valores e vivências; é constantemente renegociado, sobretudo quando novas circunstâncias, experiências e riscos emergem num lugar; e possui o potencial de confrontar, embora não necessariamente de forma antagônica, a ciência, a expertise e as práticas institucionais convencionais. A adoção do conhecimento local por parte de cientistas e profissionais permite, como desafio, apontar as imprecisões e os limites do conhecimento especializado, reorientando o trabalho de investigação e atuação institucional a partir de situações problemáticas de forma contextualizada, o que amplia a capacidade de sugerir ações contingentes e precaucionárias mais efetivas.

No campo específico dos movimentos por justiça ambiental, existem algumas correntes que vêm sendo sistematizadas por profissionais da saúde pública que incorporam o saber de trabalhadores e da população na produção de conhecimento. Dentre elas, duas vertentes podem ser destacadas: a Pesquisa Participativa Baseada na Comunidade (Community-Based Participatory Research - CBPR) e a epidemiologia popular.

A CBPR pode ser definida como uma investigação sistemática, com a participação daqueles afetados pelo problema estudado com os propósitos de educação e tomada de ação ou influên- cia quanto a mudanças sociais ${ }^{30}$. As principais características que fundamentam a CBPR são: (i) participação social; (ii) cooperação, engajamento de membros da comunidade e pesquisadores num processo conjunto no qual cada um contribui igualmente; (iii) aprendizado mútuo; (iv) desenvolvimento de sistemas de capacitação local; (v) empoderamento por meio do qual participantes podem aumentar o controle sobre suas vidas; e (vi) um equilíbrio entre pesquisa e ação. Para Leung et al. ${ }^{31}$, a CBPR não seria um método em si, mas uma forma de orientação à pesquisa que pode empregar uma série de metodologias qualitativas ou quantitativas. Com efeito, ao adotar a perspectiva da participação da população, de maneira a ressaltar as influências sociais sobre o processo saúde-doença, a pesquisa epidemiológica reafirmaria suas raízes na saúde pública, uma vez que intensifica a busca por causas a partir do indivíduo para a comunidade e para sistemas sociopolíticos; amplia as metodologias para incluir métodos de pesquisa qualitativos e participativos; e integra o conhecimento popular (local) ao conhecimento científico.

Por sua vez, o conceito de epidemiologia popular pode ser entendido como o processo pelo qual "leigos" coletam e organizam estatísticas e outras informações, ao mesmo tempo em que direcionam e refinam o conhecimento e os recursos de experts para entender a epidemiologia de uma doença ${ }^{24}$. Assim, a epidemiologia popular refere-se não somente a um processo de participação popular no que se concebe tradicionalmente como epidemiologia. A epidemiologia popular também dá ênfase a fatores sociais estruturais, interage com movimentos sociais e coloca desafios a certos pressupostos da epidemiologia clássica. O processo de investigação dessa abordagem possui diversas etapas, conforme proposição de Phil Brown, sistematizada por Haley ${ }^{32}$. Elas envolvem desde a organização da própria comunidade e a sistematização de informações e conhecimentos locais, até mobilizações para influenciar decisões e práticas de governos, políticos, indústrias, cientistas e a mídia.

Dentro dessa abordagem, existem diversas possibilidades de articulação entre pesquisadores e populações afetadas no âmbito de processos participativos de investigação em saúde ambiental. Por exemplo, Brown ${ }^{17,18}$ reforça que a configuração desta abordagem requer necessariamente a incorporação das populações ou comunidades locais afetadas em todas as etapas do estudo epidemiológico (da sua concepção à disseminação dos resultados), conforme verificado 
e descrito pelo autor no caso de Woburn. No entanto, San Sebástian e Hurtig ${ }^{33}$ reportam uma experiência de epidemiologia popular na Amazônia equatoriana na qual a participação das comunidades locais (indígenas, camponeses e ambientalistas) se restringiu apenas às fases de decisão quanto ao tipo de estudo a ser conduzido e de disseminação dos resultados encontrados. Nesta experiência, as comunidades locais optaram pela realização de um estudo epidemiológico tradicional, cuja condução até a etapa de análise de resultados ficou a cargo dos epidemiologistas colaboradores. O objetivo do estudo foi verificar a associação entre possíveis efeitos adversos à saúde coletiva e as atividades de exploração petrolíferas.

Pelos exemplos apresentados no parágrafo anterior, é possível notar que a epidemiologia popular constitui um processo de parceria entre pesquisadores e comunidades afetadas, no qual há uma distribuição de poder entre os sujeitos envolvidos quanto ao controle sobre as diversas etapas da pesquisa. Tal distribuição de poder, entretanto, pode variar de acordo com cada pesquisa, bem como com o problema específico de saúde ambiental a ser enfrentado ${ }^{33}$.

\section{Considerações Finais}

O presente artigo procurou sistematizar algumas das bases e princípios que norteiam a produção de conhecimentos sobre problemas de saúde e ambiente tendo por foco o protagonismo e os saberes locais das populações atingidas. Importantes práticas e desenvolvimentos metodológicos vêm ocorrendo no âmbito da saúde pública, impulsionadas por mobilizações e movimentos sociais com a bandeira da justiça ambiental. Tais movimentos, contudo, permanecem contra hegemônicos diante dos limites de natureza epistemológica e política de certas abordagens científicas que, em nome da pretensa objetividade e neutralidade assumido pelo modelo de ciência nor$\mathrm{mal}^{34}$, desconsideram a complexidade dos fenômenos e tendem a ocultar questões centrais relacionadas às incertezas, valores e relações de poder em jogo. Isso desumaniza a prática científica frente ao sofrimento das populações e renega o princípio precaucionário ${ }^{14}$.

$\mathrm{Na}$ segunda parte do artigo, sugerimos a incorporação de diversos princípios e práticas que assumem a importância dos saberes e mobilizações das populações atingidas, OJA e movimentos sociais em torno de problemas ambientais e de saúde. Contudo, tal proposição encontra-se longe de ser fácil e livre de problemas no interior do campo acadêmico. Pelo contrário, assumi-la é um exercício acima de tudo de consciência dos pesquisadores ao tomar partido por princípios éticos fundamentais, mas também de resgate de uma agenda que poderíamos denominar de epistemologia política presente nos compromissos históricos da medicina social latino-americana e da própria saúde coletiva. Retomando a discussão apresentada na introdução, o que está em jogo não é apenas um posicionamento de natureza político-ideológica e humanista contra os problemas do capitalismo contemporâneo, mas o reconhecimento dos limites intrínsecos de certa prática científica que despolitiza e aborda de forma reducionista questões centrais e atuais como o sofrimento humano, a mercantilização da vida e da natureza, a privatização de recursos naturais e dos bens públicos, além do desrespeito aos direitos fundamentais dos trabalhadores, mulheres, populações indígenas e afrodescendentes, dentre outras. Resgatar o saber local, situado e popular na produção compartilhada de conhecimento significa, portanto, reconhecer que a qualidade do trabalho científico e a ação política transformadora caminham juntas no enfrentamento de problemas de saúde ambiental em sociedades marcadas por desigualdades e discriminações sociais.

Tal reconhecimento não é trivial, e não deveria significar cair num reducionismo simplista e maniqueísta na análise de todas as situações envolvendo a exposição aos riscos ambientais e seus efeitos. A percepção das populações atingidas pode não ser garantia de que os nexos causais existam, ou mesmo que os grupos atingidos sempre possuam interesses legítimos diante dos conflitos e das incertezas em jogo. Todos possuímos valores e interesses, mas é a perspectiva construtivista, processual e democrática de confrontação de saberes e práticas que poderá conduzir nossas instituições científicas a enfrentar o déficit democrático, as desigualdades sociais e os riscos ecológicos globais com o mesmo empenho que busca compreender fenômenos e gerar evidências.

\section{Colaboradores}

MF Porto e R Finamore participaram igualmente de todas as etapas de elaboração do presente artigo. 


\section{Referências}

1. Porto MF. Uma ecologia política dos riscos: princípios para integrarmos o local e o global na promoção da saúde e da justiça ambiental. Rio de Janeiro: Ed. Fiocruz; 2007.

2. O'Connor J. Causas Naturales: Ensayos de Marxismo Ecológico. México: Siglo XXI; 2001.

3. Bullard R. Dumping in Dixie: race, class and environmental quality. Boulder: Westview Press; 1994.

4. Gohn MG. Abordagens teóricas no estudo dos movimentos sociais na América Latina. Cadernos CRH 2008; 21(54):439-455.

5. Santos BS. Para além do pensamento abissal: das linhas globais a uma ecologia de saberes. Novos estud. - CEBRAP 2007; 79:71-94.

6. Cordeiro H. Descentralização, universalidade e eqüidade nas reformas da saúde. Cien Saude Colet 2001; 6(2):319-328.

7. Marmot M. Social determinants of health inequalities. Lancet 2005; 365(9464):1099-1104.

8. Freitas CM. A produção científica sobre o ambiente na saúde coletiva. Cad Saude Publica 2005; 21(3):679-701.

9. Environmental Protection Agency (EPA). Integrated Risk Information System. [acessado 2012 maio 14]. Disponível em: http://www.epa.gov/iris/help_ gloss.htm

10. Stern Z. What is Environmental Risk? Zachary Stern Final Paper: Applied GIS, Spring 2007 Dr. Bjorn Sletto. East Austin Environmental Justice Project. [acessado 2012 maio 14]. Disponível em: http:// soa.utexas.edu/work/eaejp/Papers/What $\% 20$ is $\% 20$ Environmental\%20Risk.pdf

11. Lieber RR, Romano-Lieber, NS. Risco, incerteza e as possibilidades de ação na saúde ambiental. Rev Bras Epidemiol 2003; 6(2):121-134.

12. World Commission on the Ethics of Scientific Knowledge and Technology (COMEST). The Precautionary Principle. Paris: UNESCO; 2005.

13. Huet Machado JM, De Souza Porto MF. Promoção da saúde e intersetorialidade: a experiência da vigilância em saúde do trabalhador na construção de redes. Epidemiol. Serv. Saúde 2003; 12(3):121-130.

14. Martinez-Alier J, Healy H, Temper L, Walter M, Rodriguez-Labajos B, Gerber JF, Conde M. Between science and activism: Learning and teaching ecological economics with environmental justice organisations. Local Environment 2011; 16(1):17-36.

15. Jacques MG. O nexo causal em saúde/doença mental no trabalho: uma demanda para a Psicologia. Psicologia \& Sociedade 2007; 19(Ed. Esp. 1):112-119.

16. Castro HA. A vigilância ambiental em saúde de populações expostas ao amianto no Brasil. Cad Saude Coletiva 2005; 13(1):195-208.

17. Brown P. Popular Epidemiology: Community Response to Toxic Waste-Induced Disease in Woburn, Massachusetts. Sci Technol Human Values 1987; 12(3/ 4):78-85.

18. Brown P. Popular epidemiology and toxic waste contamination: Lay and professional ways of knowing. J Health Soc Behav 1992; 33(3):267-281.
19. Pierce N. Traditional Epidemiology, Modern Epidemiology, and Public Health. Am J Pub Health 1996; 86(5):678-683

20. Pierce N. Epidemiology in a changing world: variation, causation and ubiquitous risk factors. Int $J$ Epidemiol. 2011; 40(2):503-512.

21. Pierce N. Corporate influences on epidemiology. Int J Epidemiol. 2008; 37(1):46-53.

22. Krieger N. Theories for social epidemiology in the 21st century: an ecosocial perspective. Int. J. Epidemiol. 2001; 30(4):668-677.

23. Breilh J. De la vigilancia convencional al monitoreo participativo. Cien Saude Colet 2003; 8(4):937-951.

24. Akrich M, Barthe Y, Rémy C. Les enquêtes profanes et la dynamique des controverses en santé environnementale. In: Akrich M, Barthe Y, Rémy C, organizadores. Sur la piste environnementale. Menaces sanitaires et mobilisations profanes. Paris: Presses des mines; 2010. p. 7-52.

25. Wing S. Environmental justice, science and public health. Environ Health Perspect 2005; (special issue):54-63.

26. Santos M. O retorno do territorio. OSAL - Observatorio Social de América Latina 2005; 6(16):255-261.

27. Porto MF, Pivetta F. Por uma promoção da saúde emancipatória em territórios urbanos vulneráveis. In: Czeresnia D, Freitas CM, organizadores. Promoção da saúde: conceitos, reflexões, tendências. Rio de Janeiro: Editora Fiocruz; 2009. p.207-229.

28. Irwin A. Citizen science: a study of people, expertise and sustainable development. New York: Routledge; 1995.

29. Corburn J. Street Science: Community Knowledge and Environmental Health Justice. Cambridge: MIT Press; 2005

30. Corburn J. Community knowledge in environmental health science: co-producing policy expertise. Environmental Science \& Policy 2007; 10(2):150-161.

31. Leung MW, Yen IH, Minkler M. Community-based participatory research: a promising approach for increasing epidemiology's relevance in the 21 st century. Int J Epidemiol. 2004; 33(3):499-506.

32. Haley E. Methods to help communities investigate environmental health issues. Pimatisiwin. 2005; 3(1): 34-58.

33. San Sebastián M, Hurtig AK. Oil development and health in the Amazon basin of Ecuador: the popular epidemiology process. Soc Sci Med 2005; 60(4): 799-807.

34. Funtowicz S, Ravetz J. Science for the post-normal age. Futures 1993; 25(7):739-755.

Artigo apresentado em 17/04/2012

Aprovado em 07/05/2012

Versão final apresentado em 04/05/2012 